\title{
Utterance Signaling and Tonal Levels in Dominican Spanish Declaratives and Interrogatives*
}

\author{
ERIK W. WILLIS
}

\begin{abstract}
This paper examines the tonal patterns of sentences in Dominican Spanish produced in response to three pragmatic intents: declaratives, absolute interrogatives, and pronominal interrogatives. The results indicate that there are systematic variations between the three utterance types; however, the final tonal rise was not a determining factor. Distinct patterns of tonal levels distinguished each of the three utterance types. The pronominal interrogatives demonstrated a higher initial tonal value and prenuclear High tone, while the absolute interrogatives presented a significantly higher tonal value for the nuclear pitch accent. These findings identify specific intonational behaviors that vary across dialects of Spanish. Finally, the data indicate that pragmatic utterance level intonational marking of Spanish interrogatives is not limited to boundary tones as was previously suggested in the literature.
\end{abstract}

\section{Introduction}

It has been claimed that Spanish interrogatives are produced with some type of an intonational cue to signal the "interrogativity" of the utterance since Navarro Tomás' classic work (1944). The actual claims as to the acoustic nature of this intonational signaling vary in the literature, as well as the model invoked to account for the signaling. Final boundary tonal movements, typically invoked to distinguish between declaratives and interrogatives in many languages, can be neutralized in Spanish depending on the pragmatics of the utterance (Navarro Tomás, 1944; Quilis, 1987; Sosa, 1999). This final

\footnotetext{
* This paper is a revised version of Chapter 6 of my dissertation The Intonational System of Dominican Spanish: Findings and Analysis, directed by José Ignacio Hualde at the University of Illinois at Urbana-Champaign. The current version has benefited greatly from comments by Gorka Elordieta, Tim Face, Ken de Jong, and two anonymous reviewers. Any mistakes or shortcomings are my responsibility.
} 
tonal neutralization in Spanish was not considered problematic for utterance disambiguation because it has always been assumed that there was an initial boundary cue employed to signal the interrogative nature of the utterance, hence the need for the inverted interrogative marker $i$ at the beginning of an orthographic sentence (Navarro Tomás, 1944). However, there has been little comparative quantitative research into the intonational signaling of utterance types in Spanish intonation studies and the assumption of an initial higher tonal level has not been sufficiently examined.

The organization of the paper is as follows: Section 2 reviews the literature on Spanish intonation and boundary tones. Section 3 details the methodology for the study. In Section 4 I present the findings of the acoustic examination of tonal levels in declaratives, absolute interrogatives and pronominal interrogatives. Section 5 contains a discussion of the reality and variability of initial boundary tones in Dominican Spanish and a proposal to account phonologically for the findings of distinct tonal levels across the utterance types. The conclusions of the study are reviewed in Section 6.

\section{Spanish intonation and boundary tones}

\subsection{General spanish}

There are several claims concerning the intonational cues that serve to distinguish interrogatives from declaratives. Until recently, it has been accepted that the claims for interrogative tonal levels were productive in all dialects of Spanish (Quilis, 1987; Sosa, 1999), despite the lack of quantitative data for the different dialects. One set of claims suggests that absolute interrogatives are distinguished from declaratives by an increase in tonal level from the initial tonal values of the utterance (Navarro Tomás, 1944; Canellada \& Madsen, 1987; Quilis, 1993). In Navarro Tomás' original claim, an initial target is specified, but it is not clear for how long this tonal level remains at a higher level. Canellada \& Madsen (1987) claim the higher tonal level begins on the initial tone of the utterance and continues until the High tone of the first pitch accent. These analyses derive from a Pike (1945) levels type analysis that is typically reduced to three levels in Spanish (Navarro Tomás, 1944).

Recent analyses claim that differences in tonal height are evident at the High tone of the first pitch accent (Sosa, 1992, 1999; Face, 2004; Prieto, 2004, O'Rourke, 2005). This High tone is generally accepted to be part of a bi-tonal pitch accent, $\mathrm{L}+\mathrm{H}$, with variations in the analyses concerning the associated or "starred tone" of the pitch accent (Beckman et al., 2002; Face, 2002; Hualde, 2002, 2003; Sosa, 2003; Willis, 2003; Prieto, 2004). This High tone is typically realized outside the tonic syllable boundary, and has a variable alignment that is conditioned by tonal proximity and word boundary effects (de la Mota, 1995; Face, 2002; Estebas-Vilaplana, 2003). Sosa (1999) claims the pitch accent High tones of prenuclear pitch accents are produced at a higher tonal level until the nuclear pitch accent or toneme level compared to 
equivalent declarative utterances in Spanish. However, no quantitative specifics are provided. Sosa accounts for the proposed higher tonal level with an initial boundary tone labeled H\% (1999:152).

Pronominal interrogatives are reported to have a greater tonal range (magnitude) than absolute interrogatives, sixteen semitones versus eight respectively, based on speech from professional recordings of literature produced in a literary style (Navarro Tomás, 1944). However, Prieto (2004) does not find a consistent difference in tonal height between the two types of interrogatives in laboratory speech for the two speakers examined.

In the literature on Spanish intonation there are often conflicting claims concerning a final interrogative boundary tonal movement: ${ }^{1}$ a) interrogatives can be produced with a tonal fall, a suspended tone, or a final rise (see Navarro Tomás, 1944; Sosa, 1999), b) absolute interrogatives typically have a final tonal rise in laboratory speech (Sosa, 1999:200, 212), c) while pronominal interrogatives can be produced in spontaneous speech with a tonal fall, a suspended tone, or a final rise, most authors agree that the most common pattern is a final boundary fall (Sosa, 1999:144).

Prieto (2004) is based on the speech of a male and female speaker from different dialects of Peninsular Spanish in a variety of pragmatic contexts based on data of repeated productions. Prieto finds a statistically significantly higher High tone of the prenuclear pitch accent High tone in absolute interrogatives compared to declaratives, similar to that reported by Sosa (1992, 1999). The difference in means between the declarative productions and the interrogatives is $20-25 \mathrm{~Hz}$ for the male speaker and $50-55 \mathrm{~Hz}$ for the female. There is no data provided on standard deviation. What is unclear from either analysis, Sosa (1999) or Prieto (2004), is why the unassociated tone of the bi-tonal prenuclear pitch accent, $\mathrm{L}^{*}+\mathrm{H}$ in these analyses, is the target for the categorical distinction in tonal level.

Face (2004) examines absolute interrogatives in Peninsular Spanish also and reports a higher initial peak of the first pitch accent; however, he claims the increase in tonal level is phonetic. He also notes a Low tone realized on the nuclear pitch accent followed by a tonal rise in the posttonic syllable. In a later perceptual study of Peninsular Spanish (Face, 2005), results indicate that listeners are able to recognize a particular utterance based on the first tonal peak at a $95 \%$ accuracy rate.

Willis (2005) examines tonal levels between declaratives and interrogatives in Puebla Mexico Spanish and concludes that the two principal cues to absolute interrogatives are a nuclear pitch accent, $\mathrm{L}^{*}$, without any rise, and a final rising boundary tone that begins at the offset of the tonic syllable similar to that of Peninsular Spanish as reported by Face (2004).

\footnotetext{
${ }^{1}$ These claims exclude the Caribbean and Canary Islands dialects of Spanish. See Beckman et al. (2002), Navarro Tomás (1944), Sosa (1999) for a more detailed review of the final boundary tone movements in Spanish.
} 
In Peruvian Spanish, O'Rourke (2005) finds several differences between declaratives and interrogatives. Typically, both interrogative types have a higher tonal realization than similar declaratives and there is variability concerning the final tone depending on the information structure of the interrogative.

\subsection{Caribbean spanish}

Caribbean Spanish interrogatives have typically been described as having a final falling contour produced on the final toneme (Quilis, 1993; Sosa, 1999). Quilis (1993:469-470) reports that a final falling High-Low contour is common in the Spanish of Puerto Rico and the Canary Islands.

Dominican Spanish (hereafter DS) intonation is unique among studied dialects of Spanish in that declaratives can be produced with an utterance final tonal rise (see Figure 1) (Jiménez Sabater, 1975; Sosa, 1999). ${ }^{2}$ Furthermore, as illustrated in Figure 1, DS absolute interrogatives in broad focus also have an utterance final tonal rise (Willis, 2004). A final rise in declaratives and interrogatives suggests a loss of pragmatic contrast; however, Sosa notes that Dominicans never misinterpret the pragmatic intent of a rising declarative utterance with that of a question (1999:240). ${ }^{3}$
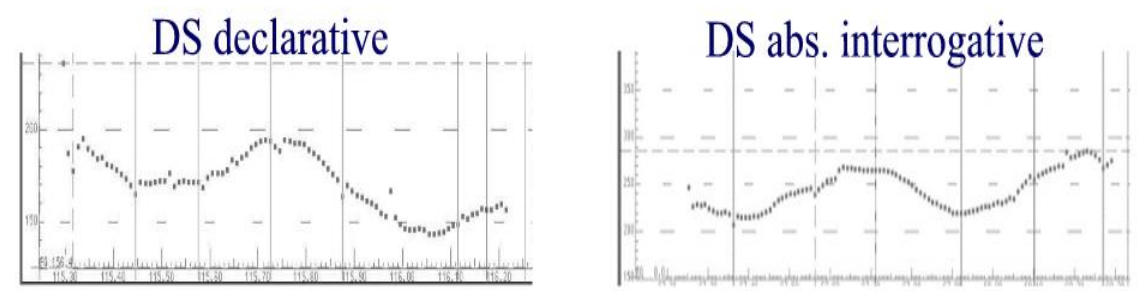

Figure 1: DS Spanish declarative and interrogative with a final tonal rise.

The current research investigates the reality of intonational cues employed to disambiguate across utterance types in Spanish, at either the initial utterance boundary or the first prenuclear pitch accent, through some type of modification of tonal height or level compared to the other utterances. This question of tonal level modification is examined in DS, a dialect of Spanish that is reported to neutralize final boundary tones across declaratives and absolute interrogatives. Since declaratives and absolutes are not misinterpreted (Sosa, 1999), and prenuclear pitch accent configurations are

\footnotetext{
${ }^{2}$ Sosa (1999) suggest the final rise only occurs in utterances to provide emphasis; however, Willis (2003) finds the final rising pattern to occur in utterances without any particular emphasis (broad focus contexts). The pragmatic meaning of this final rise is yet to be determined conclusively.

${ }^{3}$ Sosa's claim is not based on the evidence shown in Figure 1.
} 
similar (Wills, 2003), it is hypothesized that there is some type of tonal level manipulation, distinct from the final boundary tone, that contributes to utterance disambiguation in DS.

\section{Procedure}

The data for the current study comes from the speech of four female university students at the Pontificia Universidad Católica Madre y Maestra in Santiago, Dominican Republic. The speakers were screened for sociolinguistic homogeneity prior to the experiment with a biographical survey. The characteristics controlled for included gender, age (between 19-23), native speakers of the Santiago dialect, second-generation university experience, and limited contact with a second language.

The informants read a series of target sentences that were preceded by a context designed to elicit a particular response to the target sentence: declarative, absolute interrogative, and pronominal interrogative (illustrated in [1] and listed in full in Appendix 1). As illustrated in (1), the same lexical items were used to form the three utterance types for the purpose of direct comparability.

(1) Target utterance: Miraba la luna. 'She was looking at the moon.'

(a) Declarative

Contexto: ¿Qué hacía Elena ayer cuando la viste?

Respondes: Miraba la luna.

'Context: Your friend asks you, "What was Elena doing when you saw her yesterday?"

You respond: "She was looking at the moon.",

(b) Absolute interrogative

Contexto: tu mamá quiere saber qué hacía tu hermano porque no lo vio ayer.

Te pregunta ¿Miraba la luna?

'Context: Your mother wants to know what your brother was doing because she did not see him yesterday.

She asks, "Was he watching the moon?",

(c) Pronominal interrogative

Contexto: Ayer hubo un fenómeno astrológico y tu profesor de astronomía quiere saber quién lo vio.

Pregunta, “¿Quién miraba la luna?” 
'Context: Yesterday there was an astrological phenomenon and your astronomy professor wants to know who saw it.

He asks, "Who was looking at the moon [yesterday]?"

There were a total of 200 contexts read by each informant. Besides the sentences for the experimental corpus, there were 100 additional distracter sentences that included the same sentences with variations in focus structure as well as imperative sentences. The declarative corpus in the current study included 12 sentences with broad focus repeated three times each for a total of 36 target sentences per informant $(12$ sentences $\mathrm{x} 3$ repetitions $=36)$.

The interrogative corpora were based on eight sentences with both pronominal and absolute interrogative versions repeated four times each (2 interrogative types $\times 8$ sentences $\times 4$ repetitions $=64$ interrogatives). The pronominal interrogative sentences were identical to the absolute and declarative sentences except for the initial interrogative pronoun quién 'who'.

The data were recorded using a Sony DAT recorder sampled at $44.1 \mathrm{k}$ and a Radio Shack head mounted boom microphone. The microphone was located $1 \frac{1}{2}$ to 2 centimeters from the informant's lips, approximately one centimeter to the right of the mid-sagittal line and a centimeter below the lower lip.

The sentences were printed in Times New Roman script with an 18 or 20pt font and then cut and pasted onto $3 \times 5$ index cards. ${ }^{5}$ The index cards were pseudo-randomized and grouped into chunks of 25 cards, which were passed to the informant by the researcher. A break was allowed between the groups of cards. ${ }^{6}$ This methodology was used to control the speed in which the experiment proceeded and to avoid a listing intonation. The card groups of 25 forced a brief interruption and facilitated a rest break.

The entire production experiment lasted 22-35 minutes, depending on individual reading, speed and whether the informant took a break(s). The informants were asked to read the contexts and responses in a natural manner, as if they were responding to the context. Prior to the actual study, each informant performed a practice session with 16 utterances to familiarize herself with the experimental task, the recording equipment, and the types of utterances. If a context/response sequence was misread or disfluent, the subject was asked to produce it again. ${ }^{7}$ The informants were all naive as to the purpose of the experiment.

\footnotetext{
${ }^{4}$ The declarative sentences included both SoV (object being a clitic pronoun) and VO word order. There was no intonational distinction between the two types of utterances. The interrogatives were based on the SOV utterances from the declarative corpus with two additional sentences added, which were also SOV.

5 The size of font varied by the length of the context and target utterance. A long context was printed with $18 \mathrm{pt}$ font so it would fit on the card.

${ }^{6}$ Most informants stopped for a short break midway through the experiment to drink a glass of water and rest for approximately 30 seconds to a minute.

7 Typically, the disfluency involved a misread in which the speaker stopped in mid utterance to review the context.
} 
The data were analyzed using Xwaves by Entropics at the Laboratory for Computational Linguistics at the Beckman Institute, University of Illinois at Urbana-Champaign.

A number of measurements were made for each contour that reflected starting and ending points as well as turning points within the contour in order to understand the general tonal pattern of rises and falls for the three utterance types. Not all tonal targets are compared or contrasted across the three utterance types because they lack a direct counterpart due to phonological (distinct pitch accent) or syntactic structure (pronoun); however, the targets do provide valuable reference for the surrounding tones. For example, the tonal targets in the absolute interrogative reveal a general upward trend that would not be obvious when only comparing the targets for tonal comparison. The targets for comparisons of tonal levels for the three utterance types are demonstrated in Figure 2 among other targets and include: 1) the initial tonal value of the utterance (calculated as the second or third consistent F0 value), 2) the prenuclear High tone, and 3) the nuclear Low tone. ${ }^{8}$

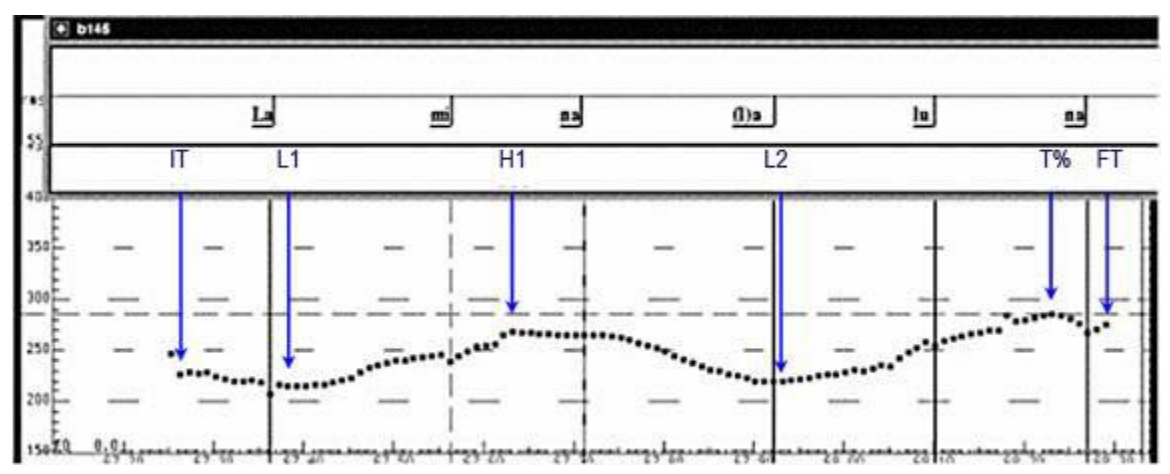

Figure 2. DS absolute interrogative sample intonational contour with landmarks illustrating the general contour pattern including for tonal comparison across declaratives and interrogatives. IT=initial tone, L1=Low tone associated with prenuclear pitch accent, $\mathrm{H1}=$ High tone associated with the prenuclear pitch accent, $\mathrm{L} 2=$ the Low tone associated with the nuclear pitch accent, T\%=the peak or High of the boundary tone (posttonic rise) and, $\mathrm{FT}=$ the final tonal value of the utterance.

\footnotetext{
${ }^{8}$ An anonymous reviewer questioned why a nuclear High tone was not also compared. As is seen in the F0 contours of the interrogative utterances, there is no nuclear High tone, only a boundary H\%; a fact also noted by Face (2004) for Peninsular Spanish.
} 


\section{Results}

\subsection{Initial tonal values}

The first claim to be tested is the proposed distinction between declaratives and interrogatives at the initial tonal values of the utterance. The greatest tonal difference is observed between the pronominal productions and the other two utterance types, and is illustrated graphically in a series of box plots in Figure 3.
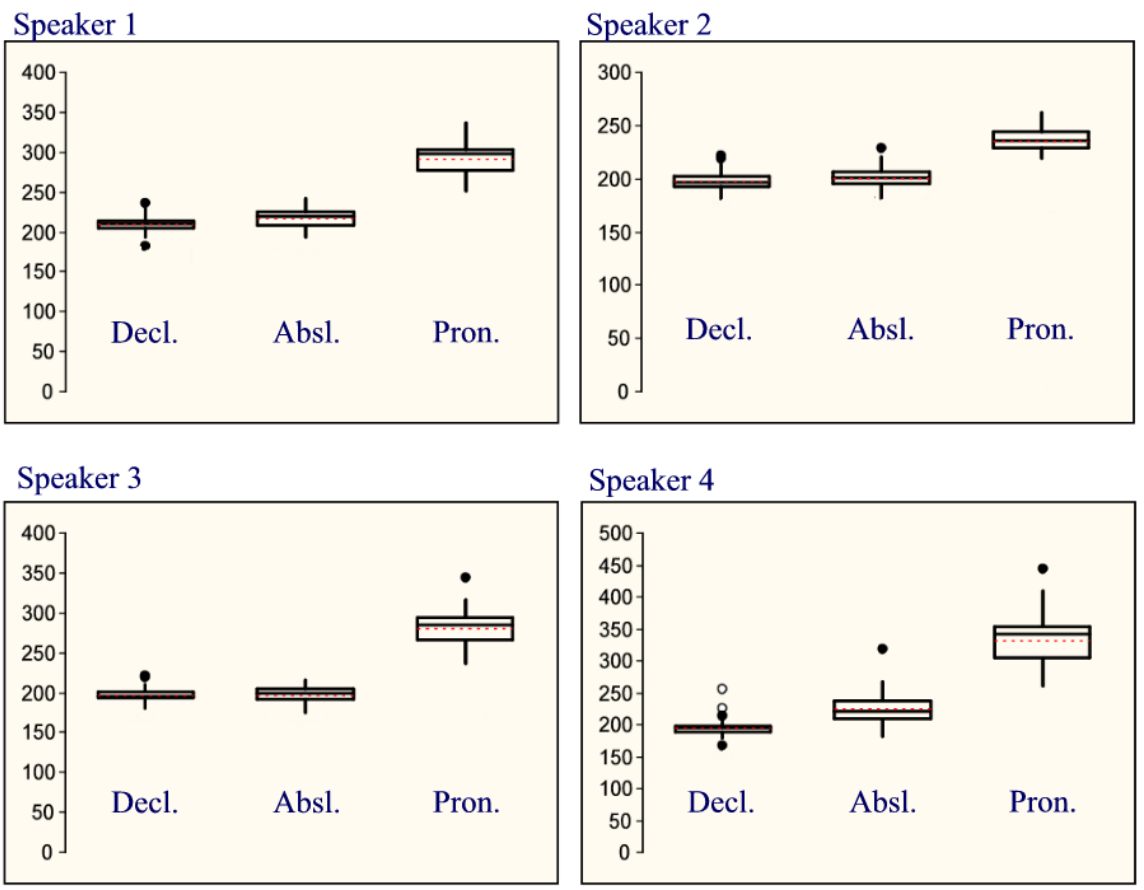

Figure 3. Box plots of initial tonal values for all speakers. Tonal values are based on raw $\mathrm{Hz}$ values.

Table 1 provides the results of an ANOVA and Bonferroni Correction factor for the initial tonal levels of the three utterance types. Three of the four speakers failed to demonstrate a statistically significant tonal distinction between initial tonal levels of declaratives and absolute interrogatives. There was no consistent tonal level distinction between declaratives and absolute interrogatives at the utterance onset (initial tonal level) for this dialect of Spanish. However, the initial tonal values of the DS pronominal interrogatives 
did demonstrate a significant difference compared to both the declaratives and the absolute interrogatives.

\begin{tabular}{|c|c|c|c|c|}
\hline \multirow{2}{*}{ Speakers } & ANOVA & \multicolumn{3}{|c|}{ Bonferroni Correction factor } \\
\cline { 3 - 5 } & & Decl.-Absl. & Decl.-Pron. & Absl.-Pron. \\
\hline 1 & $\mathrm{~F}(2,94)=307, \mathrm{p}<.0001$ & $\mathrm{~ns}$ & $\mathrm{p}<.001$ & $\mathrm{p}<.001$ \\
\hline 2 & $\mathrm{~F}(2,97)=106, \mathrm{p}<.0001$ & $\mathrm{~ns}$ & $\mathrm{p}<.001$ & $\mathrm{p}<.001$ \\
\hline 3 & $\mathrm{~F}(2,97)=289, \mathrm{p}<.0001$ & $\mathrm{~ns}$ & $\mathrm{p}<.001$ & $\mathrm{p}<.001$ \\
\hline 4 & $\mathrm{~F}(2,97)=197, \mathrm{p}<.0001$ & $\mathrm{p}<.001$ & $\mathrm{p}<.001$ & $\mathrm{p}<.001$ \\
\hline
\end{tabular}

Table 1. Statistical comparisons between the initial tonal values of the three utterance types, ANOVA and the Bonferroni correction factor. Hereafter a result of "no significant difference" ( $p>.05)$, is indicated by the label ns. Sentence types (declarative, absolute interrogative, and pronominal interrogative) were independent factors and initial tonal value was the dependent factor.

\subsection{Prenuclear High tonal values}

In several reports, the first significant difference in tonal levels between Spanish declaratives and absolute interrogatives occurs on the prenuclear pitch accent High tone, which is typically realized in the posttonic syllable (Sosa, 1992, 1999; Face, 2004; Prieto, 2004; O’Rourke, 2005; Willis, 2005). Similarly, the DS data on the prenuclear High tone examined in this study demonstrated a consistent statistically significant difference in tonal levels between declaratives and interrogatives as presented in Table 2. The differences in means between declaratives and absolute interrogatives range from $23 \mathrm{~Hz}$ (speaker 2) to $58 \mathrm{~Hz}$ (speaker 3).

Figure 4 is a series of box plots that illustrate the differences in prenuclear pitch accent tonal height between the three utterance types. For each speaker, the absolute interrogatives are produced at a higher tonal level than the declaratives, and the pronominal interrogatives are likewise higher than the absolute interrogatives. The upward scaling of the prenuclear pitch accent High tone for each successive utterance type is significant for all speakers (see Table 2). In most cases, the greatest degree of tonal range difference or magnitude of tonal range was manifest in the pronominal interrogative productions. 

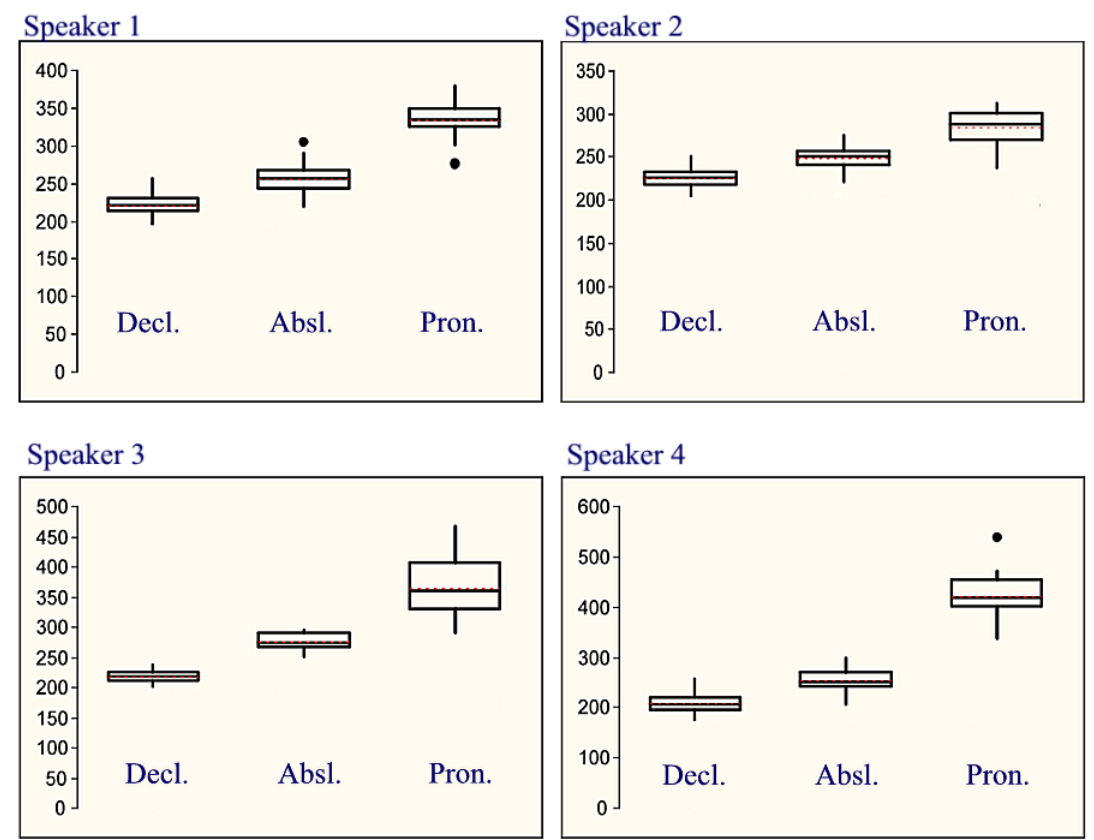

Figure 4. Box plots of prenuclear High tonal values for all speakers. Tonal values are based on raw $\mathrm{Hz}$ values.

\begin{tabular}{|c|c|c|c|c|}
\hline Speakers & ANOVA & \multicolumn{3}{|c|}{ Bonferroni Correction factor } \\
\cline { 3 - 5 } & & Decl.-Absl. & Decl.-Pron. & Absl.-Pron. \\
\hline 1 & $\mathrm{~F}(2,91)=266, \mathrm{p}<.0001$ & $\mathrm{p}<.001$ & $\mathrm{p}<.001$ & $\mathrm{p}<.001$ \\
\hline 2 & $\mathrm{~F}(2,95)=132, \mathrm{p}<.0001$ & $\mathrm{p}<.001$ & $\mathrm{p}<.001$ & $\mathrm{p}<.001$ \\
\hline 3 & $\mathrm{~F}(2,74)=191, \mathrm{p}<.0001$ & $\mathrm{p}<.001$ & $\mathrm{p}<.001$ & $\mathrm{p}<.001$ \\
\hline 4 & $\mathrm{~F}(2,78)=357, \mathrm{p}<.0001$ & $\mathrm{p}<.001$ & $\mathrm{p}<.001$ & $\mathrm{p}<.001$ \\
\hline
\end{tabular}

Table 2. Statistical comparisons between the prenuclear High tones of the three utterance types, ANOVA and the Bonferroni correction factor. Sentence types (declarative, absolute interrogative, and pronominal interrogative) were independent factors and the prenuclear High tonal value was the dependent factor.

\subsection{Nuclear Low tones}

A comparison of the nuclear pitch accent tonal levels across the three utterance types illustrated in Figure 5 revealed two important facts: 1) the absolute interrogative Low tone was significantly higher than the declaratives or pronominal interrogatives, and 2) for two speakers, pronominal 
interrogatives were at a level comparable to the declaratives, despite the previous high level of the pronominal prenuclear pitch accent.
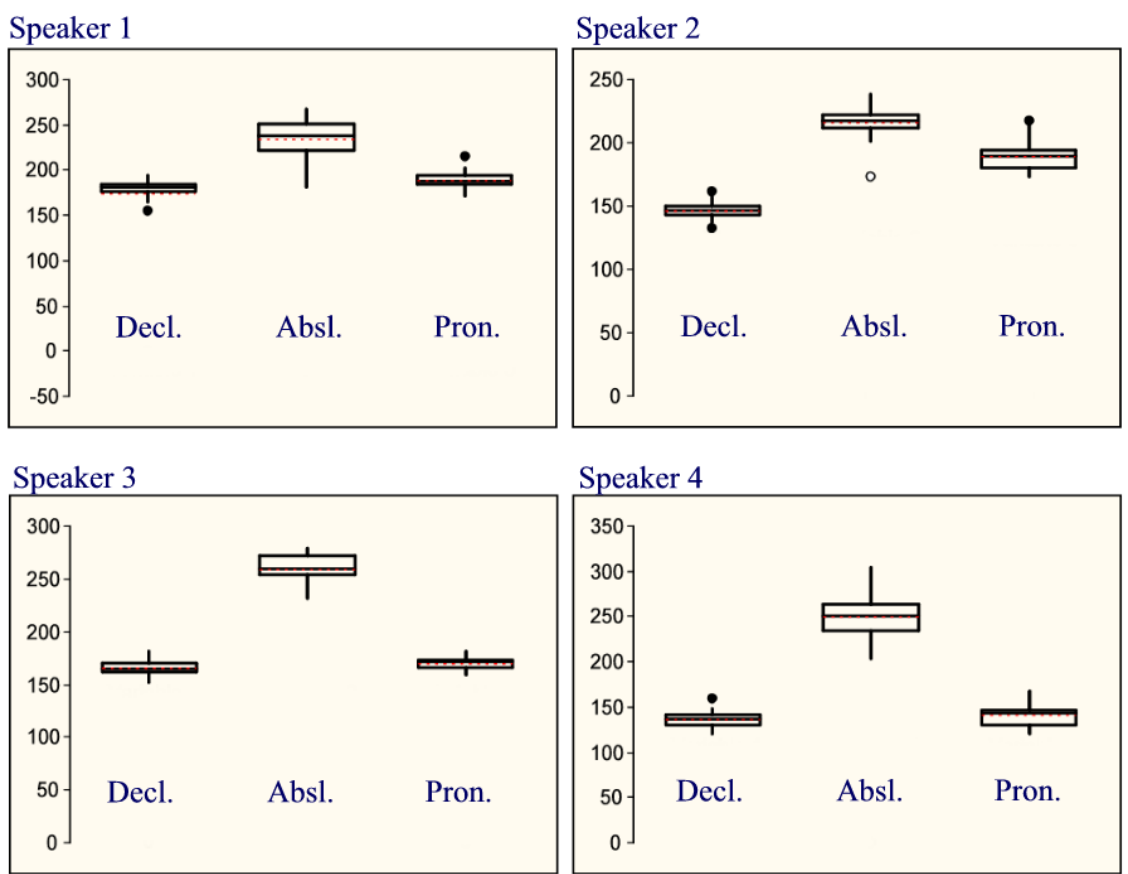

Figure 5. Box plots of nuclear pitch accent Low tones of all three utterance types in $\mathrm{Hz}$

In all cases, tonal levels of the absolute interrogative nuclear pitch accents showed statistically significant differences when compared to the declaratives or pronominal interrogatives (see Table 3 ).

\begin{tabular}{|l|c|c|c|c|}
\hline \multirow{2}{*}{ Speakers } & ANOVA & \multicolumn{3}{|c|}{ Bonferroni Correction factor } \\
\cline { 3 - 5 } & & Decl.-Absl. & Decl.-Pron. & Absl.-Pron. \\
\hline 1 & $\mathrm{~F}(2,90)=59, \mathrm{p}<.0001$ & $\mathrm{p}<.001$ & $\mathrm{p}<.034$ & $\mathrm{p}<.001$ \\
\hline 2 & $\mathrm{~F}(2,84)=352, \mathrm{p}<.0001$ & $\mathrm{p}<.001$ & $\mathrm{p}<.001$ & $\mathrm{p}<.001$ \\
\hline 3 & $\mathrm{~F}(2,69)=484, \mathrm{p}<.0001$ & $\mathrm{p}<.001$ & $\mathrm{~ns}$ & $\mathrm{p}<.001$ \\
\hline 4 & $\mathrm{~F}(2,90)=482, \mathrm{p}<.0001$ & $\mathrm{p}<.001$ & $\mathrm{~ns}$ & $\mathrm{p}<.001$ \\
\hline
\end{tabular}

Table 3. Statistical comparisons between the nuclear Low tones of the three utterance types, ANOVA and Bonferroni correction factor. Sentence types (declarative, absolute interrogative, and pronominal interrogative) were independent factors and the nuclear Low tonal value was the dependent factor. 
The tonal level of the nuclear Low tone of absolute interrogatives provides another example of one utterance type being significantly different from the other two. As seen in Figure 5, the tonal level of the nuclear pitch accent in absolute interrogatives stands out as significantly higher than either the declaratives or the pronominal interrogatives. Furthermore, the difference between the declaratives and absolute interrogatives nuclear tonal levels demonstrates a greater magnitude of tonal range compared to the range of the prenuclear High tone (see Table 4).

\begin{tabular}{|c|c|c|c|c|c|c|c|c|}
\hline Spkrs & \multicolumn{3}{|l|}{ Prenuc. High tone } & \multicolumn{3}{l|}{ Nuc. Low tone } & Range diff. comparison \\
\hline & $\begin{array}{c}\text { Dec. } \\
\text { mean }\end{array}$ & $\begin{array}{c}\text { Abs. } \\
\text { mean }\end{array}$ & $\begin{array}{c}\text { Rnge } \\
\text { diff. }\end{array}$ & $\begin{array}{c}\text { Dec. } \\
\text { mean }\end{array}$ & $\begin{array}{c}\text { Abs. } \\
\text { mean }\end{array}$ & $\begin{array}{c}\text { Range } \\
\text { diff. }\end{array}$ & $\begin{array}{c}\text { Nuc. rnge } \\
\text { increase }\end{array}$ & $\begin{array}{c}\% \text { of nuc. } \\
\text { increase }\end{array}$ \\
\hline 1 & 222 & 257 & 35 & 174 & 235 & 61 & +26 & $74 \%$ \\
\hline 2 & 226 & 249 & 23 & 147 & 216 & 69 & +46 & $200 \%$ \\
\hline 3 & 218 & 276 & 58 & 166 & 269 & 103 & +45 & $77 \%$ \\
\hline 4 & 209 & 254 & 45 & 136 & 250 & 114 & +69 & $150 \%$ \\
\hline
\end{tabular}

Table 4. Comparisons of tonal range differences of prenuclear High tones and nuclear Low tones between declaratives and absolute interrogatives and range of difference.

Based on the results of the statistical analysis and clarity of the box plots, we can conclude that the nuclear pitch accent tonal level provides a clear distinction between declaratives and absolute interrogatives in DS.

\subsection{Summary of results}

The results indicate that there are systematic variations of tonal levels that serve to distinguish between the three utterance types, which are unrelated to the direction of the final tonal movement. Absolute interrogatives show a significant difference in the tonal level of the prenuclear High tone compared to declaratives. Pronominal interrogatives differ from both declaratives and absolute interrogatives in the height of the initial tone and prenuclear pitch accent.

Figure 6 illustrates the tonal variations for each tonal specification for all three-utterance types for speaker 1. The tonal patterns for speakers 2-4 followed a similar pattern and are presented in Appendix 2. 


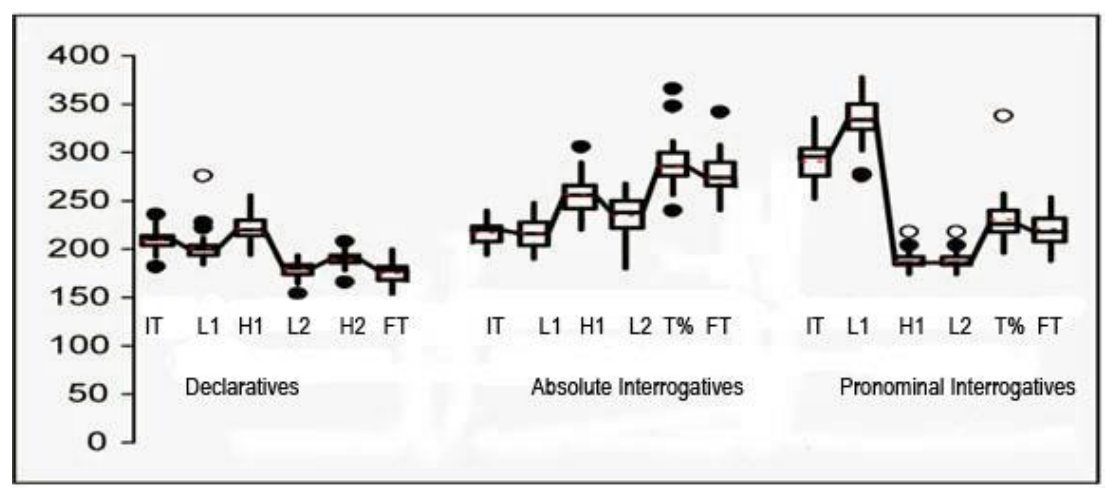

Figure 6. Box plots of comparative tonal values utterances each for declaratives, absolute interrogatives and pronominal interrogatives in Dominican Spanish for Speaker 1 speaker. Each box plot is typically based on over 30 productions of each utterance type. Similar comparative box plots for all speakers are provided in Appendix 2.

\section{Discussion}

\subsection{Declaratives and absolute interrogatives}

With the current DS data for declaratives and absolute interrogatives, we have an identical phonological structure with a distinct pragmatic intent for comparative purposes. The data in section 4.1 suggest that DS declaratives and absolute interrogatives are not distinguished from each other at the utterance initial tone as was initially proposed by Navarro Tomás (1944). Moreover, the similarity of the initial tonal values is maintained in both declaratives and absolute interrogatives through the Low tone of the prenuclear pitch accent associated with the first lexical syllable. The first pitch accent High tones of the DS absolute interrogatives are produced at a significantly higher tonal level than the DS declaratives (also found in other dialects of Spanish). While Sosa motivates this increased height of the tonal peak of interrogatives by means of an initial boundary tone ${ }^{9}$, other accounts

\footnotetext{
${ }^{9}$ Sosa (1999) claims that Spanish absolute interrogatives have an initial phrase boundary, $\mathrm{H} \%$ which serves as an upstep trigger for the first tonic syllable and subsequent tonal levels of the utterance until the nuclear pitch accent (1999:152). In this proposal, the initial High boundary has the effect of creating a distinct register of tonal height for absolute interrogatives prenuclear pitch accents compared to declaratives, similar at least in description to accounts for Hausa (Inkelas \& Leben, 1990) and Mende (Fox, 1995)(see Ladd, 1996 for additional discussion of this claim).
} 
have suggested that the tonal difference is phonetic (Face, 2004) or have not provided a tonal motivation (Prieto, 2004).

One explanation for the difference in tonal levels is to claim some type of tonal upstepping (see Beckman et al., 2002) of the prenuclear pitch accent that serves a pragmatic function of signaling interrogation in the case of absolute interrogatives. In this scenario, either the whole pitch accent is upstepped and due to some phonetic implementation the actual manifestation is limited to the trailing posttonic High tone $\left(i \mathrm{~L}^{*}+\mathrm{H}\right)$ or a more transparent analysis in which just the High tone is specified for upstep $\left(\mathrm{L}^{*}{ }_{i} \mathrm{H}\right)$. Contra the latter proposal, Willis (2003) argues that the default or unmarked prenuclear pitch accent in DS is a bi-tonal pitch accent with the Low tone more closely linked or associated with the tonic syllable producing a strong-weak association of the two tones with the tonic syllable. If the prenuclear High is the target for upstep, this would then suggest that the phonological process, upstepping in this case, is realized on the metrically weaker of the two tones and somehow "jumps" the first tone of the bitonal pitch accent.

Another difference in tonal levels between DS declaratives and absolute interrogatives occurs on the nuclear pitch accent. Both nuclear pitch accents have a falling tonal movement or Low tone on the last lexically stressed syllable of the utterance followed by a posttonic boundary rise, yet these nuclear Low tones have significantly different tonal levels between the two utterance types. Since the declaratives and absolute interrogatives have a significant difference in nuclear pitch accent tonal level, it is plausible to posit a tonal specification to account for the differences such as an upstepped nuclear Low tone or $i L^{*}$ for DS absolute interrogatives as a second tonal distinction between DS declaratives and absolute interrogatives. In Figure 7 the absolute interrogative nuclear pitch accent is labeled simply as a $i \mathrm{~L}^{*}$ primarily due to the rising nature of the contour in contrast to the $\mathrm{H}+\mathrm{L} *$ label in the declarative which is a falling contour. ${ }^{10}$

It could also be argued that the increased tonal height and the upstepped phonological specification of the prenuclear pitch accent of DS absolute interrogatives causes or triggers either a purely phonetic raising of the nuclear pitch accent Low or a phonologically upstepped nuclear Low tone. However, other dialects of Spanish such as Peninsular (Prieto, 2004) or Mexican Spanish (Willis, 2005), both with a higher High tone in prenuclear pitch accents in absolute interrogatives compared to declaratives do not have a distinct tonal level at the nuclear pitch accent.

The most compelling argument for an upstepped nuclear pitch accent analysis is purely quantitative. The pattern and alignments for the Low tone in

10 Since the contour in the absolute interrogative is moving in a general upward trend, a falling tone is not as appreciable in the actual contour. It is possible that they are distinct nuclear pitch accents with respect to a preceding High tone, but the current data does not reveal evidence regarding this question. See Willis (2003) for additional motivation for the tonal specification $\mathrm{H}+\mathrm{L}^{*}$ for the declarative nuclear pitch accents. 
both declarative and absolute interrogatives are the same with the exception of a much higher tonal level at the nuclear Low tone in absolute interrogatives (see Willis, 2003 for additional discussion). The magnitude and location of alignment of the final boundary rise is also very similar for the boundary tones of the two utterances. The only real difference in the nuclear region is the height of the nuclear pitch accent. The declarative tonal pattern proceeds in a typical downstepping pattern (see Prieto et al., 1995), while the absolute interrogative takes a step up instead of down on the nuclear pitch accent Low tone. This analysis illustrated in Figure 7 involves an upstepping of the nuclear pitch accent. The nuclear pitch accent typically recognized as the most significant tonal movement of the utterance in Spanish and an integral anchor of Navarro Tomás' (1944), toneme serves as the target for the phonologically distinguishing tonal process in the absolute interrogatives of upstepping.

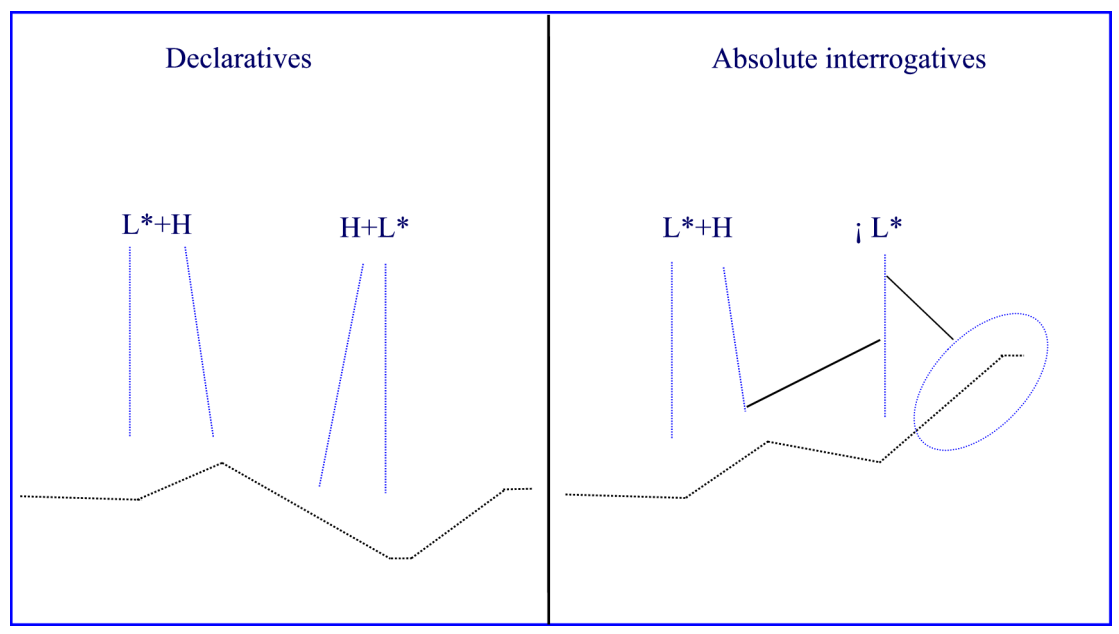

Figure 7. Schematic of DS declaratives and nuclear upstepped analysis of absolute interrogatives.

The tonal raising seen at the other tones, prenuclear High tone and postnuclear boundary tone(s) are the result of upstepping of the nuclear pitch accent. For example, an upstepped nuclear Low tone analysis could also account for the significant difference of the prenuclear pitch accent High tone in the absolute interrogatives by suggesting that the effect of an upstepped nuclear Low tone, $\mathrm{iL}^{*}$, is to phonetically raise the prenuclear High in anticipation of the metrically stronger upstepped nuclear tone (assimilatory tonal raising). Face (2002) reports a similar effect on pitch accent high tones preceding a pitch accent with contrastive focus. He notes that an effect of contrastive focus in Peninsular Spanish, in addition to raising the High of the 
contrastive pitch accent, is occasionally to raise the High tone of the pitch accent preceding the contrastive pitch accent. Furthermore, since the relationship between the nuclear pitch accent and the edges, or boundary tones, is tightly linked in Spanish (Navarro Tomás, 1944), it is likely that tonal spreading of the upstepping process applies at the nuclear pitch accent, which then spreads to the following edge tones resulting in the significantly higher edge tones. This tonal spreading from the nuclear Low tone can be explained as a phonological conditioning of the following edge tones indicated by the oval in Figure 7. The current proposal for DS motivates the significantly higher tonal level of the nuclear pitch accent not seen in other previously studied dialects of Spanish (Face, 2003; Prieto, 2004; Willis, 2005).

The role of tonal levels seen in the DS data and the above proposal is specifically for this dialect. For example, Willis (2005) does not find a difference in tonal levels at the nuclear pitch accent between declaratives and absolute interrogatives in Puebla Mexico Spanish.

What is clear from the comparisons is that there are two targets or locations, the prenuclear High tone and the nuclear Low tone, for differences in tonal heights between DS declaratives and absolute interrogatives in broad focus. Perceptual studies such as Face (2005) may also help clarify the role of prenuclear and nuclear pitch accents in DS utterance signaling.

\subsection{Absolute interrogatives and pronominal interrogatives}

As noted in the findings, the initial tonal value of DS pronominal interrogatives are significantly higher than the initial tonal value of the declaratives and absolute interrogatives. The addition of the pronoun quién 'who' to these sentences results in a change in tonal level at the utterance onset and first pitch accent compared to both declaratives and absolute interrogatives. Since the phonological structure of the interrogative pronoun does not match exactly with the metrical structure of the declarative and absolute interrogatives, we can only make tentative suggestions until further data of a directly comparable nature is collected; however, the current data does reveal systematic patterns of utterance differentiation and is in part comparable to data from Prieto (2004). Several possible accounts for the data follow.

The fact that the increase in tonal values of pronominal interrogatives occurs at the onset of the utterance, and at a significant level compared to the other utterances, suggests a tonal specification that operates at the initial utterance boundary such as $\% \mathrm{H}$. This immediate effect on the initial tonal value is what we could expect from a truly local effect of an underlying initial boundary tone, and more so when the pronominal interrogatives demonstrate a nuclear Low tone that reaches a similar tonal level compared to declaratives for two of the four speakers. 
However, there are other possibilities. It is possible that distinct pitch accents can account for the differences manifested in the initial tonal heights between DS absolute and pronominal interrogatives. For example, if the prenuclear pitch accent in absolute interrogatives is a bi-tonal pitch accent as previously suggested, the effect of the initial Low could depress the initial tonal height versus the first pitch accent of the pronominal interrogatives, which is a simple $\mathrm{H}^{*}$ (versus $\mathrm{L}+\mathrm{H}^{*}$ ). That is, the lack of an initial Low starred tone would account for the increase in height in the prenuclear accent in pronominal interrogatives. Unfortunately, we do not have empirical evidence of comparative pitch accent types (for example, monotone and bi-tonal, $\mathrm{H}^{*}$ vs $\left.\mathrm{L}^{*}+\mathrm{H}\right)$ and their effect on tonal magnitude with the pitch accent.

A unique dialectal finding of the DS pronominal interrogatives is that the tonal level of the prenuclear High tone in the DS pronominal interrogatives, i.e., the accent in the interrogative pronoun, is significantly higher compared to absolute interrogatives. Similar to the current study, Prieto (2004) examines the same type of stress structure with the quasi-minimal pair types La nena mira el loro, ¿La nena mira el loro? and ¿Dónde mira la nena el loro?, and compares the tonal level of the initial High tone (again the accent of the interrogative pronoun dónde 'where') with the High tone of the prenuclear pitch accent in the case of declaratives and absolute interrogatives (nena 'little girl').

With respect to the interrogative High tone comparisons, Prieto reports that only one speaker displayed a statistically significant tendency to pronounce higher initial peaks in wh-questions (2004:41). The DS results compared to Prieto (2004) indicate dialectal variation within the Spanish intonational system with respect to tonal height and utterance signaling.

Another possibility is that the comparative global tonal range (the difference between utterance F0 maximum and minimum) between the utterance types may serve as an additional cue to distinguish between the pronominal interrogatives and the other utterance types. ${ }^{11}$ Despite the significantly higher utterance initial and prenuclear pitch accent levels in the DS pronominal interrogatives clearly illustrated in Figure 6 and Appendix 2, the Low tone range for the declaratives and pronominal interrogatives reach a relatively similar low threshold. The result of the highest High tonal level and a similar level for the nuclear Low tone is that pronominal interrogatives have the greatest magnitude of tonal range over the course of the utterance. ${ }^{12}$ Therefore, the suggestion is that pronominal interrogatives are also distinguished by the overall range or magnitude of tonal range. Sosa (1999) also claims that both types of Spanish interrogatives have an increase in

11 This possibility was raised by Ken de Jong when the paper was first presented at the Linguistic Symposium of Romance Languages 33, Indiana University, 2003.

12 A simple comparison of prenuclear High tones as shown in Table 2 is not sufficient to characterize differences of tonal range. In the case of absolute interrogatives, the prenuclear High tone in absolute interrogatives is not the highest of the utterance nor does it reflect an F0 global maximum for the utterance (see Figures 1, 2 and 6). 
global tonal range due to an initial $\% \mathrm{H}$ boundary tone and he asserts this is the case for all dialects of Spanish. However, the DS interrogative data refute this claim as absolute interrogatives are not produced with the same degree of global tonal range as the pronominal interrogatives. ${ }^{13}$

A purely phonetic explanation for an increased initial tonal height of the pronominal utterances is that that the voicelessness of the initial segment $[\mathrm{k}]$ causes a much higher starting point. However, this account does not justify the increased tonal level of the DS tonal peak on quién 'who', which was not found by Prieto (2004).

With the current data set questions will remain concerning the role of the initial pitch accent and the proposed initial High boundary tone; however, a comparison of like structures in Prieto (2004) for Peninsular Spanish indicate that the Dominican Spanish data has a consistent and significant difference between absolute and pronominal interrogatives at the beginning of the utterance (first tonal peak).

\section{Conclusions}

The goal of this paper was to examine the intonational cues employed in the signaling of utterance types in Dominican Spanish. Specifically examined is the claim of an initial boundary tone signaling "interrogativity" in a dialect that neutralizes final boundary tonal rises in declaratives and interrogatives. The findings indicate that the three utterance types in DS in broad focus contexts are produced with distinct variations of tonal levels of specific intonational targets identified in Figure 8.

The DS absolute interrogatives were principally distinguished from the declaratives by a significantly higher tonal level of the nuclear pitch accent Low tone and secondarily by a higher High tone in the prenuclear pitch accent. The primary tonal distinction between DS absolute and pronominal interrogatives is the tonal height at the utterance onset and initial prenuclear High tone, which is unique compared to other Spanish dialects. It is proposed that these differences in tonal level (utterance onset and High tone on the pronoun quién 'who') are most likely due to an initial $\% \mathrm{H}$ boundary tone.

13 See also Ladd (1996:276-7) for additional discussion. 
(a) D.S. declaratives

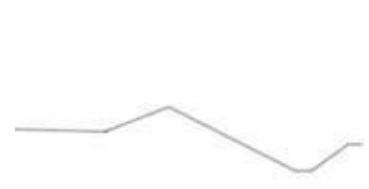

(b) D.S. abs. interrogatives

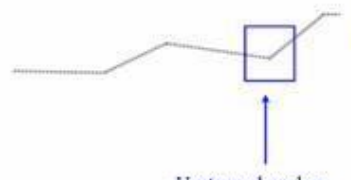

Upstepped nuclear
pitch accent, $\mathrm{iL}^{*}$ (c) D.S. pron. interrogatives

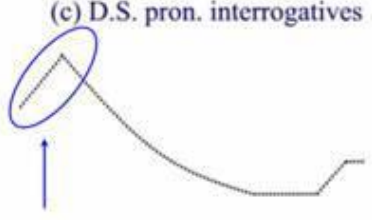

Initial High boundary tone, $\% \mathrm{H}$

Figure 8. Schematic of the basic broad focus intonational contours of declaratives, absolute interrogatives, and pronominal interrogatives in Dominican Spanish with proposed tonal targets for distinguishing tonal levels.

The proposed tonal distinctions based on tonal levels between the utterance types can characterized in simple binary distinctions as shown in Table 5.

\begin{tabular}{|l|c|c|}
\hline & $\% \mathrm{H}$ & ${ }_{\mathrm{i}} \mathrm{L}^{*}$ \\
\hline Declaratives & - & - \\
\hline Absl. inter. & - & + \\
\hline Pron. inter. & + & - \\
\hline
\end{tabular}

Table 5. Binary distinction of the three utterance types in DS based on an initial boundary tone and upstepping of the nuclear pitch accent.

The DS dialect of Spanish provides evidence that utterance types may be systematically distinguished by specific phonological configurations manifest as distinct tonal levels. Since both DS interrogatives have distinct tonal levels, due to a particular tonal behavior, the potentially ambiguous final rise of the DS declaratives does not produce an interrogative misinterpretation, since it does not also carry an upstepped nuclear pitch accent. Interestingly, the pronominal interrogative utterance, already semantically distinguished by the pronominal, maintains the original utterance initial increase in tonal height as suggested by Navarro Tomás (1944). While the DS pronominal interrogative's initial tonal height (either boundary or initial pitch accent) is not necessary for semantic purposes, the findings indicate dialectal differences in its realizations (Prieto, 2004). Finally, the current paper illustrates the roles and importance of tonal levels in the characterization of a language, and their potential role for intonational variation across dialects. 


\section{References}

Beckman, M. E., Díaz-Campos, M., McGory, J.T. \& Morgan, T.A. (2002) Intonation across Spanish, in the tones and break indices framework, Probus, 14, 9-36.

Canellada, M. J. \& Madsen, J.K. (1987) Pronunciación del español. Lengua hablada y literaria. Madrid: Castalia.

de la Mota, C. (1995) La representación gramatical de la información nueva en el discurso. PhD dissertation, Universitat Autònoma de Barcelona.

Face, T. (2002) Intonational marking of contrastive focus in Madrid Spanish. Munich: Lincom Europa.

Face, T. (2004) The intonation of absolute interrogatives in Castilian Spanish, Southwest Journal of Linguistics, 23, 65-79.

Face, T. L. (2005) F0 peak height and the perception of sentence type in Castilian Spanish, Revista Internacional de Linguística Iberoamericana, 2(6), 49-65.

Fox, A. (1995) Principles of intonational typology. In Studies in general and English phonetics: Essays in honour of Professor J.D. O'Connor (J. W. Lewis, editor), pp. 187-210. New York: Routledge.

Hualde, J.I. (2002) Intonation in Spanish and the other Ibero-Romance languages: Overview and status quaestionis. In Romance phonology and variation (C. Wiltshire \& J. Camps, editors), pp. 101-115. Amsterdam: John Benjamins.

Hualde, J.I. (2003) El modelo métrico y autosegmental. In Teorías de la entonación (P. Prieto, editor), 155-184. Barcelona: Ariel.

Inkelas, S. and Leben, W.R. (1990) Where phonology and phonetics intersect: the case of Hausa intonation. In Papers in laboratory phonology I: between the grammar and physics of speech (J. Kingston \& M. E. Beckman, editors), pp. 17-34 Cambridge: Cambridge University Press.

Jiménez Sabater, M. (1975) Más datos sobre el español de la República Dominicana. Santo Domingo, Dominican Republic: Ediciones Intec.

Ladd, R. (1996) Intonational phonology. Cambridge: Cambridge University Press.

Navarro Tomás, T. (1944) Manual de entonación española. New York: Hispanic Institute in the United States (1974. 4th ed. Madrid: Ediciones Guadarrama).

O'Rourke, E. (2005) Intonation and language contact: A case study of two varieties of Peruvian Spanish. PhD dissertation, University of Illinois at Urbana-Champaign.

Pike, K. (1945) The intonation of American English. Ann Arbor: University of Michigan publications.

Prieto, P. (2004) The search for phonological targets in the tonal space: H1 scaling and alignment in five sentence-types in Peninsular Spanish. In Laboratory approaches to Spanish phonology (T. Face, editor), pp. 29-60. Berlin: Mouton de Gruyter

Prieto, P., van Santen, J. \& Hirschberg, J. (1995) Tonal alignment patterns in Mexican Spanish, Journal of Phonetics, 23, 429-451.

Quilis, A. (1987) Entonación dialectal hispánica. In Actas del I Congreso Internacional sobre el Español de América (H. López Morales \& M. Vaquero, editors), pp. 117-164. San Juan, Puerto Rico: Academia Puertorriqueña de la Lengua Española.

Quilis, A. (1993) Tratado de fonología y fonética españolas. Madrid: Arco.

Sosa, J. M. (1992) Dialectal variation and the underlying representation of Spanish declarative intonation. In Proceedings of the 1992 annual conference of the 
Canadian Linguistic Association (C. Dyck, J. Ghomesi \& T. Wilson, editors), pp. 646-49. Toronto: University of Toronto Working Papers in Linguistics.

Sosa, J. M. (1999) La entonación del español: su estructura fónica, variabilidad y dialectología. Madrid: Catedra.

Sosa, J. M. (2003) Wh-questions in Spanish: meanings and configurational variability, Catalan Journal of Linguistics, 2, 229-247.

Willis, E. W. (2003) The intonational system of Dominican Spanish: Findings and analysis. $\mathrm{PhD}$ dissertation, University of Illinois at Urbana-Champaign.

Willis, E. W. (2004) Dominican Spanish absolute interrogatives in broad focus. In Laboratory approaches to Spanish phonology (T. Face, editor), pp. 61-91. Berlin: Mouton de Gruyter.

Willis, E. W. (2005) Tonal levels in Puebla Mexico Spanish declaratives and absolute interrogatives. In Theoretical and experimental approaches to Romance linguistics (R. Gess \& E. Rubin, editors), pp. 351-63. Amsterdam: John Benjamins.

\section{Erik Willis}

Indiana University, Bloomington

866 Ballantine Hall, 1020 E. Kirkwood

Indiana University

Bloomington, IN 47405

ewwillis@indiana.edu 


\section{Appendix 1: Target utterances}

\section{DECLARATIVES}

Marina me mira.

Manena lo lava.

Elena lo gana.

Lenini me mima.

Lorena me roba.

Lavaba la lana.

Miraba la luna.

Amaba la nena.

Alaba la mula.

Emula a la niña.

Adora la mina.

Lamina la luna.
'Marina looks at me.'

'Manena washes it.'

'Elena wins it.'

'Lenini mimics me.

'Lorena steals from me.'

'He/she was washing the wool.'

'She was looking at the moon.'

'He loved the girl (description).'

'He praises the mule.'

'He/she emulates the little girl.'

'He/she adores the mine.'

'She laminates the moon.'

INTERROGATIVES (Absolute and Pronominal)

¿Lavaba la lana? 'Did he wash the sheep?'

¿Quién lavaba la lana? 'Who was washing the wool?

¿Miraba la luna? 'Was he watching the moon?'

¿Quién miraba la luna? 'Who was watching the moon?'

¿Amaba a la nena? 'Did he love the girl?

¿Quién amaba a la nena? 'Who loved the girl?

¿Alaba la mula? 'Is he praising the mule?'

¿Quién alaba la mula? 'Who "praises" the mule?'

¿Emula a la niña? 'Is she emulating the girl?'

¿Quién emula a la niña? 'Who emulates the girl?'

¿Adora la mina? 'Who adores the mine?'

¿Quién adora la mina? 'Who adores the mine?'

¿Lamina la luna? 'Who is laminating the moon?'

¿Quién lamina la luna? 'Who is laminating the moon?'.

¿Mimaba a la niña? 'Did he spoil the girl?'

¿Quién mimaba a la niña? 'Who spoils/(ed) the baby girl?' 
Appendix 2
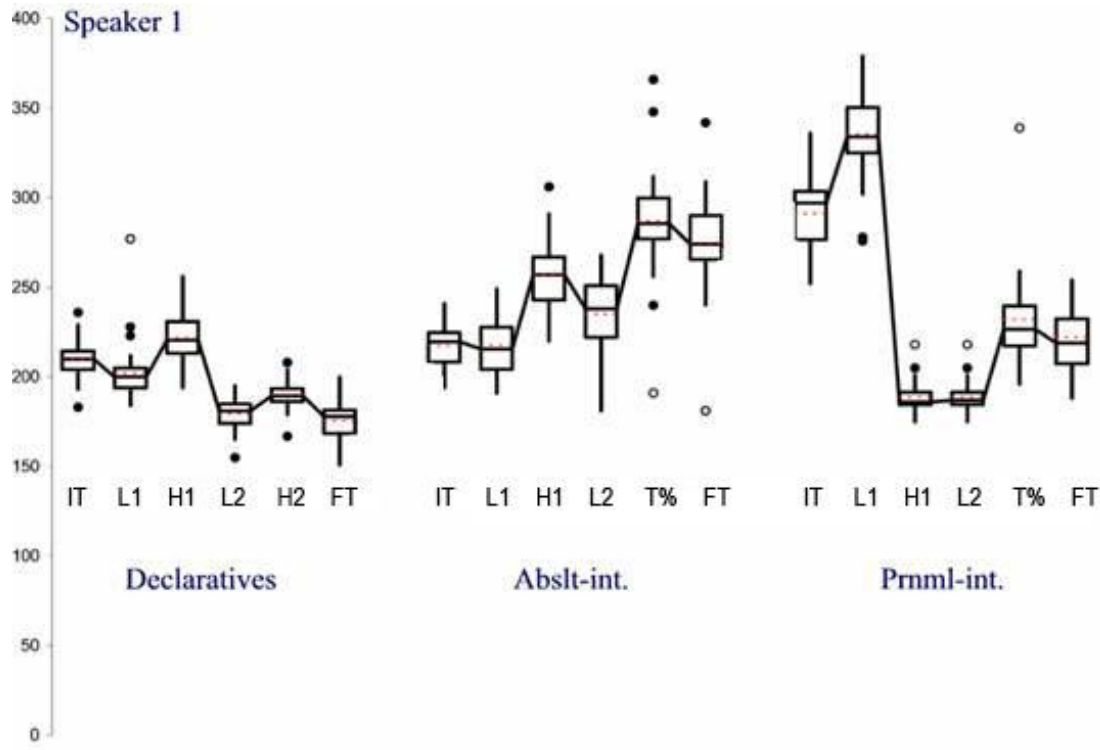

$\begin{array}{llllll}\text { IT } & \text { L1 } & \text { H1 } & \text { L2 } & \text { T\% } & \text { FT }\end{array}$

$\begin{array}{llllll}\text { IT } & \text { L1 } & \text { H1 } & \text { L2 } & \text { T\% } & \text { FT }\end{array}$

600

Speaker 2

500

Absit-int.

Prnml-int.
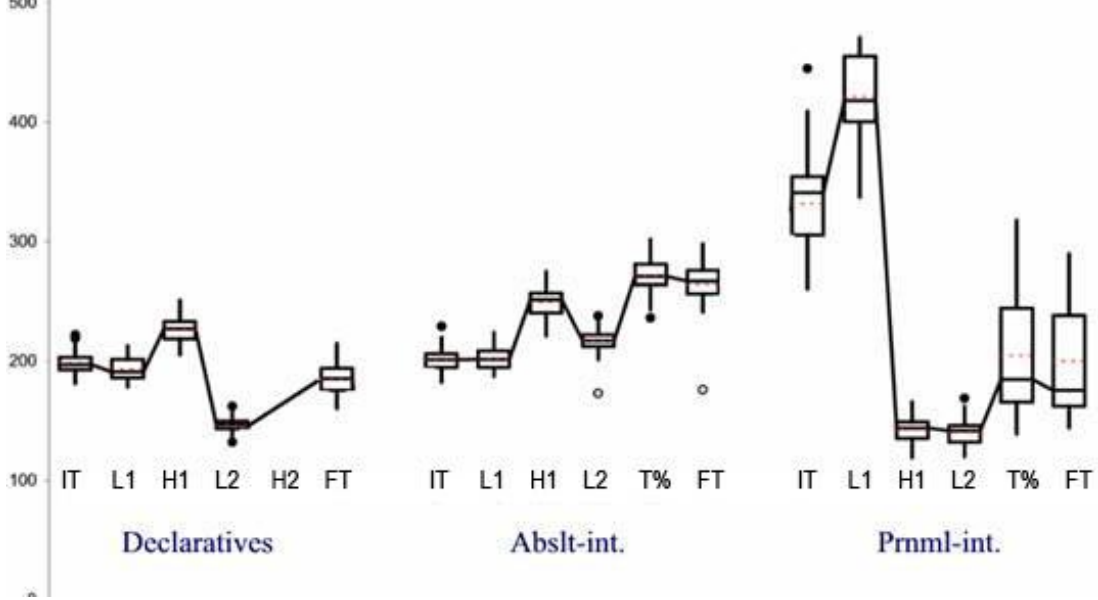

Appendix 2: Utterance comparisons for speakers 1 and 2. T\%=boundary tone, $F T=$ final tonal value of the utterance. 


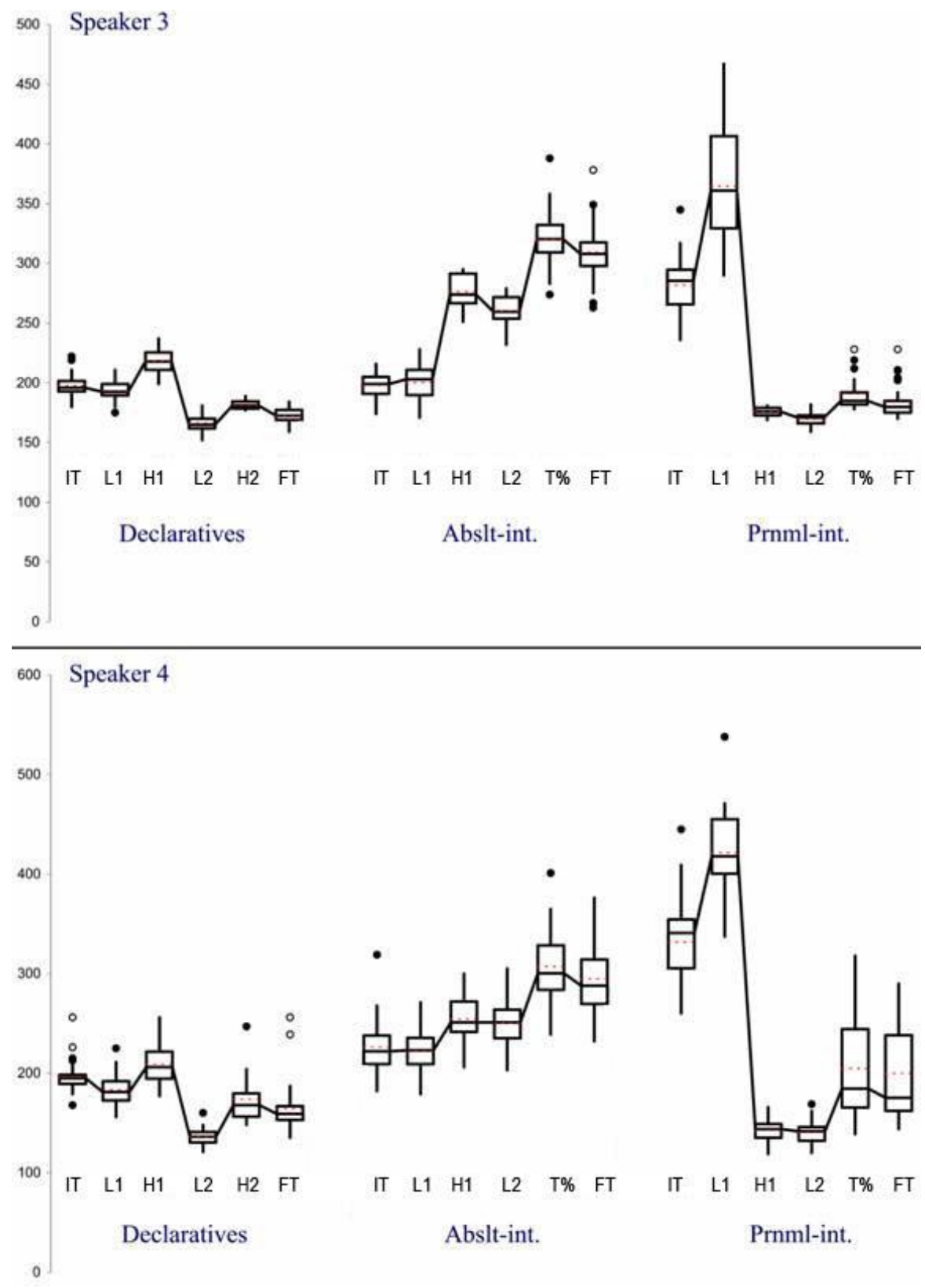

Appendix 2: Utterance comparisons for speakers 3 and 4. 